\title{
REACTIONS WITH 1.3 PROPANE SULTONE FOR THE SYNTHESIS OF CATION-EXCHANGE MEMBRANES
}

\author{
P. M. van der Velden*, B. Rupkema, C. A. Smolders and A. Bantjes \\ Twente University of Technology, Department of Chemical Engineering, P.O. Box 217, \\ Enschede, The Netherlands
}

(Received 26 April 1976)

\begin{abstract}
For several reasons it is interesting for membrane technology to introduce strongly anionic groups in membranes. Therefore the possibilities of 1.3 propane sultone were studied to modify cellulose, cellulose acetate and polyacrylonitrile.

The results showed that cellulose and cellulose acetate could be modified by a direct reaction of 1.3 propane sultone with the available hydroxyl groups. The nitrile groups in polyacrylonitrile had to be reacted first with hydrogen sulphide to give reactive thioamide groups, able to react with the sultone. These results give evidence for 1.3 propane sultone being a useful chemical for modification of polymers, its carcinogenic properties will however prevent applications.
\end{abstract}

\section{INTRODUCTION}

The most important polymers for the preparation of hyperfiltration and uitrafiltration membranes now seem to be cellulose acetate, polyamides and polyacrylonitrile. Since introduction of negatively charged groups in these types of polymers may offer some interesting possibilities, e.g. reduced membrane fouling and increased selectivity, we studied the reaction between 1.3 propane sultone and some of these polymers. Reactions with 1.3 propane sultone are favoured since strongly anionic groups are introduced. Moreover 1.3 propane sultone is very reactive; all reactions proceed at room temperature. Several authors used 1.3 propane sultone for the modification of cellulose into ion-exchangers, flocculants, adhesives [1] or for the preparation of cation-exchange membranes $[2,3] ; 1.3$ propane sultone was also used for the modification of polyamides $[1,4]$ and for ringopening polymerization with tertiary amines [5]. The synthesis of sodium sulphopropyl cellulose from alkali cellulose was studied by both Rozelle et al. $[2,3]$ (solid state reaction) and Goethals and Natus [6] (reaction in indifferent solvents):

$\mathrm{R}_{\mathrm{Col1}}(\mathrm{OH}) \cdot \mathrm{NaOH}+\underbrace{}_{\mathrm{O}}$

Rozelle et al. synthesized cellulose acetate-O-propyl sulphonic acid by a second reaction between the unreacted hydroxyl groups of sodium sulphopropyl cellulose and acetic anhydride. Membranes prepared from this polymer showed excellent performance: a flux of $6 \mathrm{~cm}^{3} / \mathrm{cm}^{2} \mathrm{hr}$ and rejections of $96 \%$ total dissolved solids, $94 \%$ ammonia and $86 \%$ total organic carbon [2]. Although the possibility of preparing cellulose acetate- $O$-propyl sulphonic acid directly from cellulose acetate was mentioned, no results were reported.

* Present address: Cordis Dow B.V., Roden, The Netherlands.
With polyacrylonitrile, 1.3 propane sultone can also be used for the introduction of anionic groups, since Gabrielyan and Rogovin [7] have found that the nitrile group can easily be converted into a thioamide group using hydrogen sulphide. The tautomeric equilibrium between the thioamide group and the thiol form offers a possibility to introduce sulphonate groups, since the $-\mathrm{SH}$ group reacts with 1.3 propane sultone according to Fischer [1] (Fig. 1).

\section{EXPERIMENTAL}

The starting polymers were cellulose (Schuchardt), cellulose acetate (Eastman Kodak E-38.3) and polyacrylonitrile (Orlon/Du Pont). The 1.3 propane sultone was supplied by Aldrich. Infra-red spectra were made with a Beckman I.R.-33 spectrophotometer and the P.M.R. spectra with a Varian XL 100 spectrophotometer.

\section{RESULTS}

\section{Cellulose and cellulose acetate}

The reactions between cellulose and 1.3 propane sultone were carried out at room temperature in acetone with $7.7 \mathrm{wt} \%$ cellulose and with a ratio of one mole 1.3 propane sultone per mole hydroxyl group. The reaction was completed by adding a large excess of sodium hydroxide solution to the reaction mixture. After $14 \mathrm{hr}$ the conversion was very low;

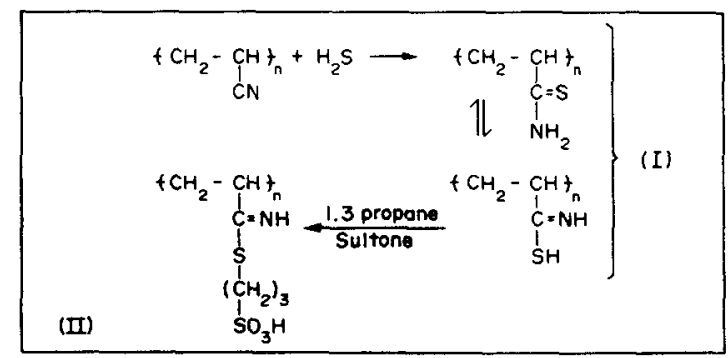

Fig. 1. Reaction sequence for the modification of polyacrylonitrile. 
Table 1. Elemental weight percentages in various cellulose-derivatives

\begin{tabular}{lccccccc}
\hline \multicolumn{1}{c}{ Polymer } & \multicolumn{6}{c}{ Element } & \\
& $\mathrm{C}$ & $\mathrm{H}$ & $\mathrm{O}$ & $\mathrm{Na}$ & $\mathrm{S}$ & Total \\
\hline Cellulose & 43.74 & 6.38 & 50.25 & - & - & 100.37 \\
Sodium sulphopropyl cellulose & 34.11 & 5.32 & 44.42 & 7.23 & 9.49 & 100.57 \\
Cellulose acetate & 48.45 & 5.74 & 46.13 & - & - & 100.32 \\
Cellulose acetate- $O$-propyl sulphonic acid & 45.05 & 5.63 & 45.54 & 1.83 & 2.73 & 100.78 \\
\hline
\end{tabular}

however after $120 \mathrm{hr}$ the degree of substitution was 0.83 (Table 1). In the i.r. spectrum of the reaction product, there was a new strong absorption at $1190 \mathrm{~cm}^{-1}$ due to the $-\mathrm{SO}_{3} \mathrm{Na}$ group. Proton magnetic resonance spectra of the reaction product dissolved in $20 \mathrm{wt} \% \mathrm{DCl} / \mathrm{D}_{2} \mathrm{O}$ showed broad bands at $\delta$-values of $c a .2 .2,3.2$ and $3.9 \mathrm{ppm}$. By comparison of these data with those of cellulose, we conclude that the P.M.R. results agree with the elemental analysis given in Table 1 and that the reaction product was sodium sulphopropyl cellulose.

Since synthesis of cellulose acetate- $O$-propyl sulphonic acid by acetylation of sodium sulphopropyl cellulose to full substitution [3] is a rather complex way to prepare anionic cellulose acetate, we studied the direct reaction between the hydroxyl groups in partially substituted cellulose acetate (C.A.) and 1.3 propane sultone. Although the hydroxyl groups in C.A. should be more easily attacked by 1.3 propane sultone than those in cellulose (C.A. being soluble in acetone), none of the i.r. spectra from the reaction products were clearly different from that of C.A. However, according to elemental analysis, small conversions were obtained after $64 \mathrm{hr}$ at room temperature and neutralization with an equimolar amount of sodium bicarbonate (Table 1).

\section{Polyacrylonitrile}

Polyacrylonitrile (PAN) can be modified through reactions with the nitrile group, e.g. by reaction with hydrogen sulphide [7] or by alkaline saponification [8]. Since the first reaction is commonly catalyzed by organic bases like pyridine and triethylamine, we studied the influence on the conversion of

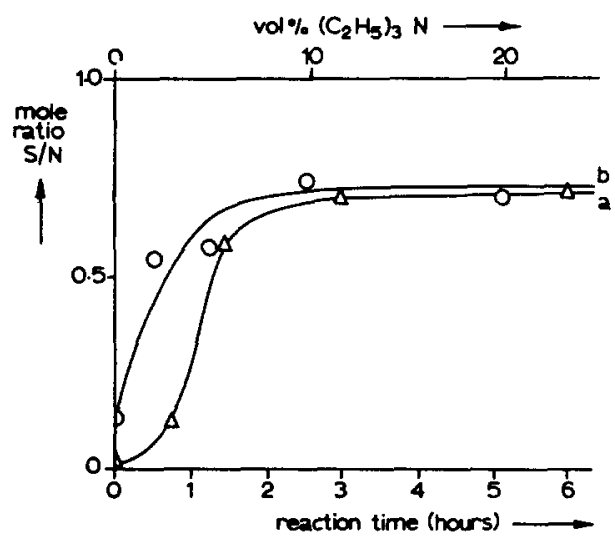

Fig. 2. Degree of modification of polyacrylonitrile with hydrogen sulphide. (a) As a function of reaction time in the presence of $20 \mathrm{vol} \%\left(\mathrm{C}_{2} \mathrm{H}_{5}\right)_{3} \mathrm{~N}$ as catalyst; (b) After $2 \frac{1}{2} \mathrm{hr}$ reaction time as a function of the amount of catalyst present during the reaction. the amount of triethylamine present during the reaction (Fig. 2). All reactions were carried out in a $10 \mathrm{wt} \%$ polymer solution in dimethylformamide at $50^{\circ}$ and were finished after $2 \frac{1}{2} \mathrm{hr}$ since it was shown that the maximum conversion had been reached (Fig. 2). Infra-red spectra of the reaction products showed an absorption at $1624 \mathrm{~cm}^{-1}$, indicating the presence of thioamide groups [7]. These results indicated that reaction between PAN and hydrogen sulphide does proceed; the conversions found with different volume percentages of catalyst are quite high. For membranes, which are not chemically crosslinked, only small conversions are possible in order to maintain mechanical strength and to prevent the polymer becoming water-soluble. For these reasons, all further reactions were carried out without catalyst. Analogous to the experiments with cellulose and cellulose acetate, the reaction with excess 1.3 propane sultone takes place in acetone, which is a non-solvent for products (I) (Fig. 1). Sulphonic acid groups were introduced by quantitative reaction of the $-\mathrm{SH}$ groups with 1.3 propane sultone, as concluded from elemental analysis of the reaction products (Table 2). Ion exchange capacity measurements by potentiometric titration gave results in good agreement with these elemental analyses (Table 2). Finally, viscometric experiments on PAN and the products listed in Table 2 showed a constant intrinsic viscosity for PAN and for the neutral polymers (IA) and (IB) in dimethylformamide, while the intrinsic viscosity of the polyelectrolytes (IIA) and (IIB) more than doubled. This viscometric behaviour also provides support for ionic character of polymer (II).

From these results, we conclude that the results of the reactions with hydrogen sulphide and 1.3 propane sultone, confirm the reaction sequence in Fig. 1.

\section{Carcinogenity of 1.3 propane sultone}

Although 1.3 propane sultone belongs to the group of alkylating chemicals, a group known to have car-

Table 2. Elemental analyses of polyacrylonitrile derivatives (I) after times of reaction with hydrogen sulphide from $\mathrm{l} \mathrm{hr} \mathrm{(A)} \mathrm{and} 2 \mathrm{hr}$ (B), and of their derivatives (II). (Chemical compositions of $I$ and II are given in Fig. 1.)

\begin{tabular}{|c|c|c|c|c|}
\hline \multirow[b]{2}{*}{ Polymer } & \multicolumn{2}{|c|}{$\begin{array}{c}\text { Elemental weight } \\
\%\end{array}$} & \multirow{2}{*}{$\begin{array}{l}\text { Mole ratio } \\
\mathrm{S} / \mathrm{N}\end{array}$} & \multirow{2}{*}{$\begin{array}{l}\text { Ion exchange } \\
\text { capacity } \\
\text { (meq/gr) }\end{array}$} \\
\hline & $\mathbf{S}$ & $\mathbf{N}$ & & \\
\hline (IA) & 3.15 & 23.08 & 0.06 & - \\
\hline (IIA) & 5.59 & 19.92 & 0.12 & 0.750 \\
\hline (IB) & 8.07 & 21.27 & 0.17 & - \\
\hline (IIB) & 12.26 & 14.69 & 0.36 & 1.906 \\
\hline
\end{tabular}


cinogenic properties, for a long time 1.3 propane sultone was not recognized as a dangerous carcinogen [9a]. However, recently rather alarming information has been published: 1.3 propane sultone produced tumours in rats, rabbits and mice when given orally, subcutaneously or by intravenous administration, resulting in death of a high percentage of these animals $[9 b, 12,13]$. Although any contact with the skin in handling 1.3 propane sultone should always be avoided $[1,9 b]$, the carcinogenic activity found for animals was exceptionally high and total prohibition of the use of 1.3 propane sultone in industry was advised [14].

Recently, the use, transport and possession of 1.3 propane sultone has been forbidden in the Netherlands [15]. Since the propyl group is not functional in our experiments, higher homologues may be used, e.g. 1.4 butane sultone, found to be much less carcinogenic $[11,13]$. However, these homologues are not commercially available, are less reactive and effect lower conversions.

\section{CONCLUSION}

Although 1.3 propane sultone is a unique chemical by which anionic groups can be introduced in cellulose-derivatives, polyamides and polyacrylonitrile, the carcinogenic properties will prevent any industrial large scale application. Since higher homologues are less carcinogenic, 1.3 propane sultone may be replaced by a higher homologue in the reaction given above.

Acknowledgement-The authors thank $\mathrm{Mr}$. W. Lengton for assistance with the potentiometric titrations.

\section{REFERENCES}

1. R. F. Fischer, Ind. Engng Chem. 56 (3), 41 (1964).

2. North Star Research and Development Institute. Water pollution control research series, Report 17020 EFA 10/70 (1970).

3. L. T. Rozelle, J. E. Cadotte, B. R. Nelson and C. V. Kopp, Appl. Polym. Symp. 22, 223 (1973).

4. D. Dieterich, W. Keberle and H. Witt, Angew. Chem. 82, 53 (1970).

5. S. Hashimoto and T. Yamashita, Polymer Journal 8, 15 (1976).

6. E. J. Goethals and G. Natus, Makromolek. Chem. 93, 259 (1966).

7. G. A. Gabrielyan and Z. A. Rogovin, Vysokomolek. Soedin. 6 (5), 759 (1964).

8. H. Bayzer and J. Schurz, Z. phys. Chem. N.F. 13, 30 (1957).

9. N. I. Sax, Dangerous Properties of Industrial Materials, Van Nostrand, Reinhold, New York (a) 3rd ed. (1968); (b) 4th ed. (1975).

10. B. L. van Duuren, S. Melchionne, R. Blair, B. M. Goldschmidt and C. Katz, J. natn. Cancer Inst. 46 (1), 143 (1971).

11. H. Druckrey, H. Kruse, R. Preussmann, S. Ivankovic, Ch. Landschütz and J. Gimmy, Z. Krebsforsch. 75, 69 (1970).

12. U. Wölcke, Chemische Carcinogene im Laboratorium, Bundesanstalt für Arbeitsschutz und Unfallforschung. Dortmund (1974).

13. G. W. Fischer, R. Jentzsch, V. Kasanzewa and F. Riemer, J. prakt Chem. 317, 943 (1975).

14. R. Audran and G. Siou, Cah, Notes docum. 81, 467 (1975).

15. J. Government of the Netherlands ("Staatsblad"), no. 97 , 11 March 1976. 